\title{
Silencios y olvidos sobre los judíos progresistas chilenos (1938-1964)
}

\author{
Valeria Navarro-Rosenblatt
}

\author{
Universidad Católica Silva Henríquez. Santiago de Chile \\ vnavarro@ucsh.cl
}

Title: Silences and forgetfulness about Chilean progressive Jews (1938-1964)

Resumen: El presente artículo sigue la trayectoria de las dos instituciones progresistas judias existentes en Chile: la Sociedad Progresista Israelita (19381951) y el Centro Cultural Scholem Aleichem (1951-1964). Junto con explorar las actividades e ideas principales de cada una, la pregunta que persiste a lo largo del artículo es: ¿por qué se generó un silencio en torno al mundo progresista judío chileno? Las respuestas no son sencillas, ambas instituciones enlazan entre sí la historia del progresismo judío latinoamericano, la política comunista durante la Segunda Guerra Mundial y la Guerra Fría, y la historia chilena, cada una con sus matices y eventos importantes.

Palabras claves: progresismo judío - Sociedad Progresista Israelita - Centro Cultural Scholem Aleichem - judios comunistas - Chile

\begin{abstract}
An important question underlines the following pages, why a cover of silence covered the experience of progressive and communist Jews in Chile? This article follows two Jewish progressive institutions from Chile: Sociedad Progresista Israelita (1938-1951) and Centro Cultural Scholem Aleichem (19511964). These two institutions gathered the main questions of Jews in the country: how to face the crucial events of international and national politics, during the Second World War and the Cold War. By revealing how the institutions worked and the type of activities in which they expressed their ideology, we can start to find the answer to why, in the Jewish Chilean context, their progressive voice was silenced.
\end{abstract}

Keywords: progressive Jews - Sociedad Progresista Israelita - Centro Cultural Scholem Aleichem - communist Jews - Chile

Recepción: 10 de agosto de 2019. Aceptación: 24 de agosto de 2019 .

(Archivos, año VIII, $\mathrm{n}^{\circ}$ 15, septiembre de 2019, pp. 37-52) 
En 1956 se publicó el libro Historia de la colectividad israelita de Chile (Senderey, 1956) como parte de las celebraciones del cincuentenario de la vida judía organizada en el país. Al revisar las páginas de esta obra observamos anécdotas, reflexiones, fechas y las actividades que caracterizan a los diferentes grupos inmigrantes, como su vida social, deportiva y cultural. ${ }^{1}$ De forma paralela, ese mismo año, una institución judía comunista conocida como el Centro Cultural Scholem Aleichem se encontraba en uno de sus momentos más productivos y activos sin embargo, no aparece ningún rastro o presencia de esta organización en el libro de Senderey.

La Historia de la colectividad israelita evitaba hacer mención a la palabra "comunistas" o cualquiera de sus acepciones, prefiriendo el uso del eufemismo "progresistas", para englobar a la izquierda y a quienes estaban en agrupaciones distintas a las instituciones centrales judías. Este silencio significó que el Centro Cultural, en su momento de mayor apogeo, fuese excluido de la narrativa sobre la historia judía chilena. Un silencio que resuena en la actualidad cuando nos preguntamos por la relación entre los chilenos judíos y los comunistas, los chilenos judíos y los socialistas.

El presente artículo explora la experiencia del mundo progresista y comunista chilenos, a través de la trayectoria y relevancia de la institución judía progresista, en un inicio llamada Sociedad Progresista Israelita (SPI), y posteriormente Centro Cultural Scholem Aleichem (CCSA). Se busca retratar la vinculación del mundo judío chileno con la ideología comunista, su desarrollo cultural a través del ídish y su inicial cercanía a la Unión Soviética, a lo largo de las décadas de 1930 a 1960. Interesa evidenciar cómo la sociedad progresista fue un colectivo de iniciativas y actividades que se reflejó en la diversidad del judaísmo chileno.

Hay que mencionar que la colectividad judía chilena se formó en la primera década del siglo XX, con la llegada de judíos sefaradies provenientes del Imperio Otomano y ashkenazies del Imperio Zarista. Hacia 1930 había aproximadamente 3.700 personas que declaraban profesar la fe judia. En 1940 la cifra había aumentado a 8.600, por el influjo de los refugiados alemanes ante la persecución nazi (Matus, 1993). Para 1950 había cerca de 30.000 judíos en Chile. Las primeras organizaciones se establecieron a partir de 1906-1920, y a partir de la declaración Balfour de 1917 la colectividad judia chilena se había caracterizado por su fuerte identificación con la causa sionista (Navarro-Rosenblatt: 2018).

En la medida que las fuentes disponibles lo permitan, el presente artículo trazará la historia de la institución mencionada. Desde sus

1. El libro fue un encargo del Comité Representativo, el cual le entregó a Moisés Senderey los documentos necesarios para realizar la obra. 
inicios como Sociedad Progresista Israelita, entre las décadas del 30 y el 40, cuando la actividad se centró en la figura de Jacobo Pilowsky, fundador de la sociedad. En un segundo momento, como Centro Cultural Scholem Aleichem, durante los años 50 y 60, cuando se transformó, cambio de nombre y se vinculó con el contexto nacional, plasmando sus actividades en el periódico Tribuna Judía.

De acuerdo con Elizabeth Jelin (2002), la memoria es un proceso en continua construcción y reinterpretación. Aquello que en un momento consideramos como fijo, nos muestra que aún existe flexibilidad, posibilidades de descubrimiento y sorpresas en la historia. En especial cuando pensamos en el mundo judío chileno, que se constituye, en gran parte, por lo que se ha transmitido en la historia "oficial" o la historia de los organismos centrales de la institucionalidad judía. El libro Historia de la colectividad israelita de Chile a lo largo de los últimos 50 años, se ha convertido en referencia necesaria para toda investigación sobre la vida judia en Chile. Es la "historia oficial", la referencia sine quanon, el inicio de toda historia posterior sobre los judíos chilenos. ${ }^{2}$ La ausencia del SPI y el CCSA en este libro borró a dichas instituciones del canon de lo judío chileno, relegándolo a memorias familiares y a anécdotas inconexas de la historia judia y chilena.

Explorando la memoria, los silencios y los olvidos en la narrativa "oficial" del colectivo judio chileno, se busca valorar la experiencia de la Sociedad Progresista Israelita (SPI) y el Centro Cultural Scholem Aleichem (CCSA). Las memorias, y archivos familiares destacan entre las fuentes que permiten recuperar aquello que fue silenciando en la década de los 50, un silencio que fue fortaleciéndose con los años y con los traumas posteriores vividos por la sociedad chilena. Tal como explica Steve J. Stern, la historia oral permite revelar qué procesos llevan a las personas a contar su verdad como lo hacen, y qué es lo que se encuentra dentro de la memoria colectiva $(2009,31),{ }^{3}$ así lo oral suple una narración para aquellos fragmentos que construyen al mundo judío progresista chileno, dispersos e inconexos en archivos internacionales, y en los recuerdos de las familias.

De este modo, para ir más allá de esta historia "oficial", se debe buscar y preguntar de forma activa por posibles lagunas o silencios, en especial en la transmisión de la memoria entre distintas generaciones. A veces basta con verbalizar esa pregunta para abrir los silencios, traer las

2. Para comprender la celebración del cincuentenario de la Colectividad Judía Chilena, revisar Navarro-Rosenblatt (2018: 69-91).

3. Stern explica a través de la metafora de la caja de la memoria para explicar aquello que entra en el espacio de la memoria colectiva como un discurso oficial o como fragmentos sueltos. 
instituciones dejadas en la retaguardia, activar la memoria y recuperar parte de esa historia oculta o perdida. En otras ocasiones, la pregunta genera más incertidumbres al evidenciar el espacio dejado por aquello que efectivamente quedó sin transmitir de una generación a otra y cuya ausencia, ahora revelada, marca mayores misterios, o tristezas más profundas. La historia judía chilena presenta muchos hitos relevantes que se revelan si se les pone en diálogo con la historia nacional, pero esta búsqueda tiene que ser intencionada, gestada desde la pregunta y memoria activa (Jelin, 2002).

La historia del SPI y CCSA revela ambos tipos de reacciones: frente a la pregunta activa por la institución, encontramos aquellos descendientes que conocen su historia, dispuestos a hablar y otros que descubren un vacío significativo en la transmisión de la memoria colectiva, de su familia y su entorno. Así, para la familia Pilowsky/Peliowsky, ${ }^{4}$ hablar del SPI y el CCSA es traer a la vida algunos de los momentos más activos y profundos de la vida judía de sus miembros. Jacobo Pilowsky, su hermano Beinish Peliowsky y sus hijos, fueron miembros activos de la organización y atesoran sus recuerdos como parte importante de su ser judío chileno. Por otra parte, para las familias Brodsky o Zimerman, la existencia del Scholem Aleichem la institución en la cual participaron sus padres no se recuerda y es una pregunta que abre interrogantes. Sus casos serán explicados con detalle en este artículo, como muestra de un problema más general.

\section{La Sociedad Progresista Israelita y el Comité Representativo de la Colectividad Israelita de Chile}

La Sociedad Progresista Israelita fue fundada en 1938, en el centro de Santiago de Chile, y aparece en los registros históricos disponibles en ese año, cuando su presidente, Jacobo Pilowsky, escritor idishista comunista, publicó una nota en el periódico Mundo Judio criticando la pasividad y autoproclamación del "Comité Central" (de la colectividad israelita) que se adjudicaba ser la voz oficial de los judíos en Chile. ${ }^{5}$ La carta decía representar alrededor de cien personas judías progresistas. Bajo el espectro de la amenaza nazi y la creciente persecución a los judíos en Europa, Pilowsky lideró este colectivo entre 1938 y 1950 y la SPI desarrolló actividades culturales sobre la situación de la Unión Soviética o sobre los escritores judíos de la época. Pilowsky mantuvo

4. Los primeros que llegaron a Chile fueron Jacobo Pilowsky y dos de sus hermanos. Beinish llegó varios años después y al registrar su nombre lo escribieron con otras vocales. Esta es la razón por la cual el apellido se escribe distinto.

5. Más detalle se puede encontrar en Valeria Navarro-Rosenblatt (2017). 
un nexo directo con la colectividad israelita de Chile, promoviendo la colaboración entre distintos sectores políticos para hacer frente en conjunto a la amenaza nazi, y en particular para organizar mejor la ayuda hacia los refugiados judios que llegaban a Chile.

No se conoce mucha información sobre el origen y funcionamiento interno del SPI, sólo se han podido relevar algunos actos importantes. Un pequeño registro literario nos indica cómo pueden haber sido las reuniones semanales de esta institución: Beinish Peliowski (2005), hermano de Jacobo Pilowsky, relata en sus memorias Amores congruentes, el inmigrante integrado cómo se reunían en casas de los dirigentes, tomaban té, conversaban y jugaban naipes. Luego enfatiza: "La Sociedad Progresista tiene reuniones abiertas. [...] el trabajo que desarrolla es fundamentalmente cultural", entre ellas, charlas y actos sobre literatura y actualidad. Asimismo, la preocupación sobre los sucesos internacionales aparecía en todos los espacios progresistas de la época.

En abril de 1941 Pilowsky asistió en Buenos Aires al Congreso que fundó la Federación de Entidades Culturales Judias (Idisher Cultural Farband, conocida como ICUF). La iniciativa había comenzado el año 1937 en París, en un Congreso de Cultura Judía, donde se acordó la creación de federaciones para nuclear a la población judia "progresista" de cada país. En la fundación del ICUF en Argentina participaron representantes de Uruguay, Brasil y Chile, que estuvo representado por Jacobo Pilowsky en nombre de la SPI. En dicha ocasión el ICUF se declaró "judeo-progresista" y funcionó como una más entre las organizaciones antifascistas de la época. Ese fue el comienzo de una continua relación entre Pilowsky con el icufismo argentino que se mantendrá durante los años de la SPI y continuará cuando, en 1951 se convirtió en Centro Cultural Sholem Aleichem.

Después del congreso de 1941, al regresar a Chile, en un banquete organizado para recibirlo, Pilowsky realizó una presentación explicando las razones por las cuales era importante adherir a esta iniciativa internacional en contra del fascismo, que ya comenzaba a manifestarse en América Latina. Pilowsky difundió lo experimentado en Argentina y el significado de la participación de la SPI en el marco de ICUF.

Desde sus inicios, la SPI tuvo una relación ambivalente con el "Comité Central", que a partir de 1940 pasó a llamarse "Comité Representativo de la Colectividad Israelita de Chile". Esta institución reunía a los representantes de todas las organizaciones judias chilenas, incluyendo distintas regiones del país, y tenía un marcado carácter sionista. A partir de 1938, Pilowsky actuó como presidente y representó la voz de los judios progresistas en la prensa y en cada reunión referida a temas como la inmigración judía y el avance del nazismo. La colaboración entre la SPI y el Comité Representativo durante este período refleja la política 
internacional frente-populista, también acordada en el ICUF de París. En Chile, la SPI buscó agruparse con otras fuerzas judeo-progresistas, y llamaba a la unidad a instituciones como la Asociación de Jóvenes Israelitas (AJI), Poalei-Sion, Liga pro-Palestina (hebrea) o Bicur Joelim. Esta convocatoria a la unidad dentro de la colectividad judia incentivada por la SPI demuestra la fortaleza que tenía en su entorno la línea comunista que, con los Frentes Populares a partir de 1935, promovia la formación de alianzas antifascistas en Francia, España y también Chile (Gómez Chamorro, 2010: 82-84). Durante el conflicto internacional, la Sociedad Progresista Israelita fue incluida en el listado de organizaciones pertenecientes al Comité Representativo entre 1940 y 1952. Esto significaba que ciertos representantes de la SPI asistían periódicamente a las reuniones directivas del organismo central, presentando la voz y la opinión del mundo judeo-progresista. Asimismo, la SPI mantuvo una presencia importante en el Vaad Hajinuj (Comité de Educación), porque fueron los gestores del área cultural ídish en el Instituto Hebreo.

Durante los años de la Segunda Guerra, la SPI mantenía una profunda preocupación por asistir a los inmigrantes judios recién llegados a Chile, y al mismo tiempo desarrollaba actividades sociales y culturales. Entre 1939 y 1951 se realizaron una serie de conferencias, eventos y fiestas que mostraban la multiplicidad de intereses e iniciativas de sus miembros. ${ }^{6}$ El 1 de mayo de 1939, por ejemplo, la SPI celebró su primer aniversario junto al día del trabajador. En los siguientes años, la celebración conjunta de ambos acontecimientos tomó una dimensión de festejo y reivindicación de la cultura ídish de izquierda en Chile. En esas ocasiones se ofrecian banquetes familiares acompañados de música, literatura y teatro en ídish. Una invitación de agosto de 1939 convoca a la comunidad a participar de un "banquete de despedida" al presidente Jacobo Pilowsky, quien viajaba a Estados Unidos. Cabe mencionar que Pilowsky mantenía una fuerte relación con el idishismo norteamericano, en especial con el área teatral. A su regreso, en marzo de 1940, la SPI realizó un té en su honor en la calle Nueva de Matte 138, y en diciembre Pilowsky brindó una conferencia sobre sus "Impresiones de viaje por Estados Unidos y Canadá”. Esta secuencia de eventos, con un claro protagonismo de esta figura, dan cuenta de su lugar como referente intelectual para el judeo-progresismo chileno.

En el marco de un trabajo común con otras fuerzas antifascistas, la SPI formó parte del conjunto de organizaciones chilenas que actuaron en solidaridad con los republicanos durante la Guerra Civil Española. La SPI se sumó al Movimiento pro Emancipación de la Mujer Chilena 
(MEMCH), la Sociedad de Escritores de Chile (SECH), la Federación de Estudiantes de Chile, la Federación de Estudiantes Secundarios, la Asociación Médica de Chile, el Colegio de Abogados, la Confederación de Trabajadores de Chile y la Asociación de Empleados de Chile, entre otras. La SPI fue la única organización judia que estableció un vínculo entre la situación de los judíos refugiados, la persecución en Europa y los eventos en España. Incluso antes de la llegada de refugiados españoles y judios a Chile, la SPI fomentó una campaña en favor de unir fuerzas para la movilización colectiva. En noviembre de 1938, a partir del llamado de Pilowsky a boicotear el rol "representativo" del Comité, como antes se ha referido, y en el contexto de la "Noche de los Cristales Rotos" en Alemania, la SPI lideró una manifestación para crear conciencia entre los judíos chilenos del peligro nazi y, mediante un folleto que repartió masivamente, convocó a una reunión a realizarse el 30 de enero de 1939 para tratar diversos temas: lucha anti-hitlerista, inmigración, defensa del pequeño comerciante judío y ayuda a España Gobiernista. ${ }^{7}$ La SPI criticaba la "apatía" de los judios chilenos que permanecían "impasibles" frente a "la desgarradora tragedia" sufrida por "las víctimas de la locura parda". La apatía manifestada, probablemente en referencia al Comité Representativo, es un indicador de que, a pesar del llamado a la unidad, persistía una profunda disputa entre ambas instituciones. Para enfrentar al nazismo, la SPI insistía con el trabajo conjunto y un boicot a nivel nacional de los productos alemanes. ${ }^{8}$

En cuanto al problema de la entrada de inmigración judía en esos años, la SPI señalaba que la entrada de un judío a Chile era la oportunidad de "arrancar a uno más de los nuestros de las garras del fascismo alemán" y llamaba a la movilización, recordando el precepto judío: "Quien salva la vida de una persona, salva al mundo". Las condiciones de Chile, además, eran propicias porque el gobierno del Frente Popular, liderado por Pedro Aguirre Cerda, entre 1938 y 1941, tenía posturas "menos limitadas y más desprovistas de prejuicios" que otros gobiernos de la región. ${ }^{9}$ La SPI también menciona las disputas internas a raíz del "affaire de la inmigración judía" de 1939-1940. Este conflicto se generó cuando se supo que cónsules y agentes chilenos en el extranjero pedian dinero a cambio de otorgar visas. El caso apareció en la prensa y derivó en una fuerte discusión en el Parlamento. El diputado comunista Natalio Berman (Nes-El, 1988), en línea con el progresismo chileno, fue

7. Folleto "San Diego 114", en YIVO RG-116, Chile. Territorial Collection, Carpeta Sociedad Israelita.

8. YIVO, RG-116.

9. Una visión crítica de la actitud de los funcionarios del gobierno de Pedro Aguirre Cerda se puede encontrar en Schindler (2017). 
uno de los más enérgicos en cuestionar la labor de los funcionarios "de dudosa moral". El "affaire" terminó con el cierre de puertas para los refugiados judíos en el momento más trágico y necesario para salvarlos (Brahm, 2012). Este cierre de fronteras chilenas coincidió con una política generalizada en el continente americano. Por último, se puede presumir que el folleto de la SPI fue preparado y distribuido antes del 24 de enero de 1939, fecha en la que tuvo lugar un gran terremoto que destruyó varias ciudades del sur de Chile, como Chillán y Concepción. Por lo tanto, no se consideraba ni sabía aún la precariedad económica que surgiria pronto en Chile debido a ello.

El tercer punto de interés para la SPI, la "defensa del pequeño comerciante judio", denunciaba cierta fobia antisemita "oportunista". La preocupación por el trabajo del "semanalero" judío refería a los vendedores ambulantes y a plazos, principal ocupación de los inmigrantes judios en Santiago de Chile. A pesar de las favorables condiciones políticas que reconocía la SPI, denunciaba la existencia de prejuicios y estereotipos, potenciados a la luz del contexto europeo y la propaganda antiinmigración que circuló con el problema de las visas y la llegada de refugiados israelitas al país.

Finalmente, el folleto llamaba a la "ayuda de la España Gobiernista". $\mathrm{El}$ interés por la lucha republicana en el entorno judío significaba para la SPI reforzar la democracia y el compromiso de los judíos chilenos con la causa:

La cuestión española nos interesa a todos, sin distinción de credos políticos. En España se está jugando la suerte de la democracia y como consecuencia, el destino del pueblo judío. Hasta este momento, es muy poco lo que la colonia judía ha hecho en favor de la España leal. Es de lamentar que solamente nuestra sociedad haya colaborado en la ayuda a este pueblo heroico. No queremos ser los únicos; deberá crearse un Comité Pro-Ayuda a España Gobiernista que represente a todas las sociedades judias. ${ }^{10}$

En los años 40, la SPI realizó numerosas charlas de temas de interés para sus miembros, denotando su pensamiento político pro-soviético. En 1940, cuando el conflicto en Europa habia alcanzado ribetes internacionales y comenzaba la llamada "Guerra de Invierno" tras la invasión de la Unión Soviética a Finlandia, la SPI realizó una conferencia sobre "La nueva política de la URSS y el conflicto con Finlandia". En abril de

10. Folleto "San Diego 114", en YIVO RG-116, Chile. Territorial Collection, Carpeta Sociedad Israelita. 
1941 se realizó un evento en honor a David Bergelson, por sus 30 años de creación literaria. Bergelson era en 1941 uno de los más famosos y populares escritores en ídish, considerado como uno de los herederos de los tres clásicos: Scholem Aleichem, I.L. Peretz y Mendele Mocher Sforim (Appelfeld, 1996). En los años de la Segunda Guerra Mundial, Bergelson integró el Comité Antifascista Judío de la URSS, que buscaba reunir el apoyo de los judíos de otros países para el Ejército Rojo (Redlich, 1969; Rubinstein, 2001). En noviembre de 1944, la SPI invitaba a celebrar el 27 aniversario de la Revolución Rusa, actividad en la que habló César Godoy Urrutia, diputado comunista por el distrito de Santiago (en 1941 y 1948), y Jacobo Pilowsky, presidente de la SPI. La participación de Godoy muestra la conexión entre la Sociedad Progresista Israelita y el Partido Comunista Chileno. En esta ceremonia hubo actuaciones de artistas judios de Buenos Aires que visitaban la ciudad y participaron en diversas instituciones como la Unión Israelita Polaca de Chile. ${ }^{11}$ E1 30 de abril de 1945 se celebró el "Día del Trabajo", que también marcaba el noveno aniversario de la SPI. En dicha ocasión, participaron el diputado comunista Natalio Berman, Jacobo Pilowsky, Aaron Vantman, Oscar Halpern, Moisés Zimerman (por la Unión Israelita Polaca), Lila Adler, y David Lacks. Las palabras de Berman muestran el rol de gestora de la unidad que habia tenido la SPI porque "no ha escatimado ningún esfuerzo para lograr la sagrada unión, olvidando sus diferencias de toda indole y por haber facilitado la labor común de ayuda a las Naciones Unidas, labor que debe transformarse actualmente en ayuda directa a nuestras victimas de Europa" (Nueva Época, 1945). Sin embargo, el dialogo entre los distintos sectores judíos chilenos se quebraría en el contexto de la Guerra Fría.

\section{De la formación del Centro Cultural Scholem Aleichem al aniversario del levantamiento del Ghetto de Varsovia}

En 1951 la SPI invitó a su último evento como tal, porque daba paso a la fundación de una nueva organización: el Centro Cultural Scholem Aleichem. La ceremonia tuvo lugar en octubre, en la nueva sede de la organización, situada en la calle París del centro de Santiago. La celebración incluyó la visita de Marie Rabinowitz, hija de Sholem Aleichem, y su esposo el escritor y periodista ídish Ben Zion Goldberg. El programa artístico incluía fiesta y baile. El evento mostraba la expansión del sector progresista, pero a su vez estaba condicionado a otras circunstancias.

Por una parte, significaba el inicio de una nueva etapa, donde luego de

11. Archivo Central de la Historia del Pueblo Judío, colección Chile, carpeta 486, Unión Israelita Polaca. 
catorce años finalizaba la política de diálogo y colaboración de la SPI con los sionistas del que fuera Comité Central, y luego Comité Representativo de la Colectividad Israelita de Chile. Como se explicó anteriormente, los años de funcionamiento de la SPI se corresponden con la época del Frente Popular y la colaboración entre partidos políticos, y también de organizaciones judias de distintas ideologías democráticas en Chile.

Por otra parte, la SPI estaba ligada al Partido Comunista Chileno que, ilegalizado, entró en la clandestinidad en 1948. Recordemos que esto se debió a la Ley de Defensa de la Democracia, o coloquialmente denominada "Ley Maldita", del gobierno de Gabriel González Videla, que quitó autoritariamente a los militantes del padrón electoral y expulsó a los diputados comunistas de sus cargos (Casals: 2013). Si bien no contamos con documentación al respecto, con ayuda de otras fuentes, podemos suponer que la SPI tuvo que restringir su expresa adhesión al comunismo y su ligazón con la militancia. Entonces el cambio de nombre, adoptando el de "Scholem Aleijem", referente indiscutido de la literatura idishista, y la inauguración de una nueva sede pudieron haber sido parte de aquel proceso.

En 1951, el enfoque ideológico que manifiesta el Centro Cultural Scholem Aleichem persiste en su simpatía y adhesión al mundo soviético. Las tensas relaciones con el Comité Representativo o la Federación Sionista disminuyen y en 1953 se cortan definitivamente, evidenciando el impacto de la Guerra Fría. Esto se expresa en la desaparición del CCSA del listado de instituciones judías del Comité Representativo. No contamos con un registro claro por el cual dar cuenta de esta separación, pero existen dos indicadores clave. Por una parte, el hebreo como idioma nacional y la política de migración al Estado de Israel, desde su creación en 1948, fue adoptada con énfasis por el sionismo, mientras el progresismo, afincado en la defensa del idishismo, rechazó adherir a esa transformación cultural. Entre 1953 y 1954 se discutió si en el Instituto Hebreo se debía o no enseñar ídish, junto con el hebreo, pero en 1955 el programa de enseñanza incluía el hebreo y no el ídish. Esto puede ser explicado por un cambio generacional en el que las nuevas generaciones nacidas en Chile no aprendieron el ídish como parte de su educación judía. Así mismo el ídish y los pequeños círculos culturales en este idioma en Chile mantenian una competencia con el mundo hebreo sionista (Kaczewiak: 2019, 10). En sus memorias, Beinish Peliowsky recuerda una conversación posterior a la Segunda Guerra Mundial en la que el autor presenta la rivalidad entre el ídish y el hebreo, una disputa entre el nacionalismo burgués y una identidad cultural de las masas populares judías. Explica que "el yidish (sic) es un símbolo de lucha por el progreso, una bandera de lucha contra los sionistas. Ellos desprecian el yidish, el idioma materno de las masas judías, para realzar el hebreo" 
(Peliowsky, 2005: 139). Para la década del 50, tras el establecimiento de Israel y la pérdida del mundo ídish por la Segunda Guerra Mundial, la disputa entre ambas fuerzas estaba inclinada hacia el hebreo. Este es uno de los primeros antecedentes para la posterior desaparición de las instituciones judias progresistas presentadas en este artículo.

Por otra parte, el juicio y asesinato de los trece escritores judios en la Unión Soviética en agosto de 1952 y la campaña del "antisemitismo soviético" provocaron un cisma, tal como sucedió en diversas organizaciones judias comunistas del mundo. ${ }^{12}$ Los hechos ocurridos en la Unión Soviética durante los últimos años de Stalin fueron desestimados por los militantes del Partido Comunista, quienes en particular negaron el carácter antisemita de los hechos. Este fue el hito que ocasionó el quiebre entre Jacobo Pilowsky, presidente de la SPI, y el Partido Comunista. Pilowsky deja su militancia en el partido y se aleja del Centro Cultural Scholem Aleichem, continuando una vida en los espacios judios intelectuales. Posteriormente migra a Israel. Un caso relacionado, con matices distintos, tiene lugar en Argentina cuando en 1952 se termina de separar el ICUF de la AMIA/DAIA.

Mientras se alejaba de las instituciones sionistas chilenas, el Centro Cultural Scholem Aleichem profundizó sus lazos con el ICUF Argentina para fortalecer y nutrir su contenido cultural idishista con enseñanza del idioma, teatro, prensa y círculos de lectura femeninos.

El periódico Tribuna Judía, fundado en el año 1951, pronto se convirtió en la voz del Centro Cultural Scholem Aleichem. Los escasos números del periódico que se han podido consultar reflejan una cosmovisión y activismo ligados a la política cultural del Partido Comunista Chileno. En una editorial, Tribuna Judía se presenta a sí misma como un espacio necesario de la colectividad judia, que pueda reflejarla desde distintos ángulos y "sin espíritu estrecho ni partidista". ${ }^{13}$ Esa falta de una publicación plural y "sin espíritu estrecho ni partidista" es un eufemismo en referencia a las discrepancias con los sectores sionistas que se expanden en de las instituciones. En el número 8, de marzo de 1954, Tribuna Judia denuncia la falta de espacio para la cultura ídish en la prensa tradicional, que se encontraba en manos de "sectores dominantes de la colectividad" y estima el suyo como "el único órgano progresista en el seno de la colectividad", cuya tarea principal era "vincular estrecha-

12. Se trata del juicio y asesinato a 13 escritores el 12 de agosto de 1952 en la Unión Soviética que marcaban la cúspide de la cultura ídish. Asimismo, en 1953 se desarrolló el llamado "Complot de los Doctores", en que se acusó a un grupo de doctores judíos de intentar asesinar a Stalin y otros líderes soviéticos.

13. “Tribuna Judía. Hacia Adelante”, Tribuna Judía, nº 8, marzo de 1954. 
mente a los judíos de Chile con el pueblo chileno, del que lógicamente se considera parte integrante". ${ }^{14}$

Desde la primera editorial Tribuna Judia se presentaba como espacio del progresismo y la cultura judía pero también como parte de la sociedad en general, y enfatiza en la libertad, la fraternidad y en que "no pueden sernos ajenos" los problemas de otros pueblos. El clima de gran preocupación, por la proscripción del Partido Comunista y por la pérdida de figuras como el poeta Pablo Neruda y otros que tuvieron que exiliarse, subyace en los contenidos de las notas principales de esta publicación. Tribuna Judia permite identificar algunos temas y actividades relevantes durante los principales años de actividad del CCSA, que incluía actos conmemorativos por el Levantamiento del Ghetto de Varsovia, círculos femeninos de lectura, clubes para jóvenes, actos por la paz, clases de ídish para niños y jóvenes, y la difusión de obras teatrales en ídish.

El teatro fue una de las principales actividades en esta nueva etapa. Entre noviembre de 1953 y marzo de 1954 Tribuna Judía dedicó numerosas páginas a la gira de la compañia teatral argentina del Idischer Folks Teater (IFT, Teatro Popular Judio), adherido a ICUF y vinculado al Partido Comunista. La presencia del IFT en Santiago fue un evento destacado por la prensa a nivel nacional: El Mercurio, Las Últimas Noticias, La Nación, Mundo Judio, Las Noticias Gráficas, El Debate, Los Tiempos, Noticias de Última Hora, La Tercera, y las revistas Eva, Vistazo y Ecran, es decir, la prensa chilena de distintas lineas editoriales. Por lo tanto, esa visita le generó al CCSA una gran difusión como organización cultural de la sociedad chilena, y también tuvo resonancia entre las instituciones judías. El grupo del IFT presentó la obra Madre Coraje de Bertolt Brecht, que representaba los costos humanos de la guerra en la sociedad. Brecht escribió su obra en 1939, frente al avance del fascismo en el mundo; pero el mensaje denunciaba la crueldad de toda guerra, y era también significativo en 1953, en el contexto de la Guerra Fría.

Los actores y actrices dieron charlas abiertas sobre los significados de su experiencia de trabajo artístico-comunitario con contenido social y su vinculación con el teatro argentino. A partir de la visita del IFT, e inspirados en esa compañia, se formó un grupo de teatro ídish en el CCSA. En agosto de 1954 se presentó el "Conjunto teatral chileno-judío, Talía", con obras de I.L. Peretz, y de Scholem Aleichem. De acuerdo con las palabras de Tribuna Judía, este grupo de teatro ídish "ha cumplido un anhelo sentido dentro de la colectividad" porque ha despertado a la colectividad del "pesado letargo cultural" en el que se encontraba sumida. La labor de este grupo teatral chileno se extendió durante toda 
la década de 1960, presentando obras como Di Yidische Froi fun Minsk, Man un Froi, Yurtsait-Lijt, Far Der Tir, o A Dokter, entre otras.

El teatro fue una de las más relevantes actividades del CCSA, porque significó una acción concreta de difusión cultural ídish dentro del mundo judío chileno, pero también en el arte y cultura de Chile.

En 1964 se realizó la última actividad del Centro Cultural Scholem Aleichem que se ha registrado. El acto recordaba el $21^{\circ}$ aniversario del Levantamiento del Ghetto de Varsovia y, como siempre, importantes personalidades harian uso de la palabra. El presidente de la CCSA, el arquitecto comunista Abraham Schapira, dio un discurso dónde retrató la ideología de la institución y su compromiso con el destino de las masas populares no judias. Schapira recogía el legado del SPI y los primeros años del CCSA; la lucha por la justicia social, la lucha de clases y la alianza entre los judíos y otras minorias para combatir la discriminación. En un claro mensaje contra el sionismo, argumentaba que era un deber para los judios ser conscientes de las amenazas del fascismo encubiertas en el lenguaje del nacionalismo. Las palabras de Shapira fueron publicadas en el diario El Siglo, reconocido periódico comunista.

Después de este evento, no contamos con registros de actividades del Centro Cultural Scholem Aleichem. Sólo podemos hacer conjeturas identificando los principales eventos políticos que pudieron afectar a la organización y determinar su desaparición. Por una parte, 1964 fue un año de gran efervescencia política en Chile con las elecciones presidenciales que tuvieron un fuerte componente de anticomunismo en su propaganda. A través de los partidos politicos de centro derecha, como el Partido Democracia Cristiana, y de derecha, como el Partido Nacional, se llevó adelante una campaña de desprestigio en contra del mundo comunista y el comunismo chileno, que abarcó toda la prensa de derecha, en especial El Mercurio y El Diario Ilustrado (Casals, 2013: 48). En este contexto, se puede asumir que los miembros del Centro Cultural Scholem Aleichem dedicaron su energía a la campaña electoral de Salvador Allende. La política nacional chilena, por lo tanto, debe haber consumido parte del esfuerzo político de los miembros del Centro Cultural, alejándolos de las actividades étnico-culturales, como el teatro. Tras la elección del presidente demócrata-cristiano Eduardo Frei Montalva en 1964, la política chilena siguió un curso de radicalización y división política.

\section{Conclusión: el silencio y sus olvidos}

Con el paso de los años y la distancia temporal, la existencia de esta institución fue olvidada en la historia de la colectividad judía chilena. Dos procesos paralelos explican la memoria del Centro Cultural Scho- 
lem Aleichem. Por una parte, hubo una acción deliberada de parte de la comunidad judía central de omitir la existencia de esta institución. Como se mencionó en la introducción, en 1956, cuando el Centro Cultural Scholem Aleichem se encontraba en sus años de prolifica actividad, también se celebraban los 50 años de la comunidad judia organizada en Chile (1906-1956). Desde el Comité Representativo se decidió realizar un libro conmemorativo sobre la vida judia en Chile. La obra fue encargada al escritor argentino Moisés Senderey y así nació el libro Historia de la colectividad israelita de Chile. A pesar de que en ese momento el CCSA estaba en plena actividad, no aparece mencionado. Más aún, cuando se menciona al que fuera el presidente de su predecesora, la Sociedad Progresista Israelita, Jacobo Pilowsky, se lo menciona como "progresista", entre comillas, quizás un eufemismo para decir comunista o tal vez utilizado para no comprometerlo, debido a la ilegalidad del Partido Comunista Chileno. Esta ausencia es significativa porque "las borraduras y olvidos pueden ser producto de una voluntad política de olvido y silencio para ocultar y destruir pruebas y rastros, impidiendo así recuperaciones de memorias en el futuro" (Jelin: 2002). Esa voluntad de quitar de la memoria judía chilena al CCSA tuvo el fin de delimitar "lo judío" en la sociedad chilena. Para la comunidad organizada, en especial tras las persecuciones antisemitas en la Unión Soviética, era inconcebible que se incluyera a comunistas judios, porque ellos habian negado los sucesos de 1952.

Sin embargo, una segunda arista del olvido del CCSA fue la falta de transmisión por parte de sus protagonistas, que no dejaron testimonios de sus actividades, ni siquiera en los entornos familiares. En una entrevista realizada al escritor Roberto Brodsky, se le preguntó sobre la participación de su padre, Moisés Brodsky, como presidente del Centro Cultural Scholem Aleichem. Para su sorpresa, ni Roberto ni ninguno de sus hermanos sabía de esta institución, ni del rol que tuvo su padre en ella. Esta ausencia del CCSA se repite en los hijos de otros de sus miembros. De igual forma, la familia Zimerman, hijos de Jacobo, uno de los gestores culturales del teatro ídish, atesoraban las fotografias de su padre en las obras de teatro, pero no asociaban esta iniciativa con una organización judeo-comunista. En este sentido una parte de la historia, la militancia política de los integrantes del grupo de teatro, fue obviada y silenciada dentro del entorno familiar. La hija de Isidoro Lipfschitz, tampoco retiene en su memoria la importante disidencia que significó esta institución y su recuerdo son los cursos en ídish que impartian.

El silencio en la historia que presentan las familias Brodsky, Lipfschitz y Zimerman es un reflejo de la falta de transmisión entre una generación y otra, donde lo que no se relata es aquello que produce un dolor. Por ejemplo, la vida de Moisés Brodsky en el Scholem Aleichem 
está marcada en los años siguientes con una distancia entre lo judío y lo comunista, así como con la vorágine que significó para su familia los años 70 con el gobierno de Allende, el golpe de Estado y el posterior exilio y precariedad en Buenos Aires y Venezuela. Por lo que la experiencia del CCSA quedó tamizada por el dolor de la experiencia posterior. La misma vorágine unió a Beinish Peliowsky y su familia con la tragedia chilena, y al igual que los Brodsky los encaminó al exilio.

Elizabeth Jelin explica que en caso de olvido el silencio funciona como un elemento de protección luego de experiencias traumáticas. "También hay voluntad de silencio, de no contar o transmitir, de guardar las huellas encerradas en espacios inaccesibles, para cuidar a los otros, como expresión del deseo de no herir ni transmitir sufrimientos" (Jelin, 2002: 31). Este es el caso del silencio que imperó en el CCSA.

Es relevante, por lo tanto, revelar no sólo la existencia de las instituciones judias progresistas como la Sociedad Progresista Israelita y el Centro Cultural Scholem Aleichem, sino recalcar cómo el silencio existente fue parte también de los procesos históricos chilenos que marcaron la división entre izquierda y derecha. Si bien a partir de 1964 las instituciones judias progresistas dejan de funcionar, la participación de judíos de izquierda y comunistas en particular continuó en la política chilena, y tuvo relevancia en el gobierno de Salvador Allende. Luego del golpe de Estado de 1973, la vida judia comunista chilena y la izquierda judia en general sufrieron una profunda crisis, fomentando el silencio y el olvido sobre la experiencia judia comunista entre la década de 1930 y 1960.

\section{Bibliografía}

Appelfeld, Aharon (1996), "Foreward", en David Bergelson y Golda Werman, The Stories of David Bergelson. Yiddish Short Fiction From Russia, Syracuse: Syracuse University Press.

Bethell, L. (2002), "Chile, 1930-1958", en Historia de América Latina, vol. 15: El Cono Sur desde 1930, Barcelona: Crítica.

Brahm, E. y J. Montes (2012), "El Frente Popular y la inmigración judia a Chile: de la apertura al cierre total", Revista Chilena de Derecho, vol. 39, $\mathrm{n}^{\circ}$ 3, pp. 909-917.

Casals, Marcelo (2013), "La "larga duración" del autoritarismo chileno. Prácticas y discursos anticomunistas camino al golpe de Estado de 1973", Revista de Historia y Geografia, no 29, pp. 31-54.

Gómez Chamorro, María Soledad (2010), "Factores nacionales e internacionales de la política interna del Partido Comunista de Chile (1922-1952), en Augusto Varas, Alfredo Riquelme y Marcelo Casals (eds.), El Partido Comunista en Chile: una historia presente, Santiago: FLACSO-Usach.

Jelin, Elizabeth (2002), Los trabajos de la memoria, Buenos Aires: Siglo XXI. 
Kaczewiak, Mariusz (2019), "Yiddish in the Andes. Unbearable distance, devoted activists and building Yiddish culture in Chile", Jewish Culture and History, DOI: 10.1080/1462169X.2019.1658460.

Lederhendler, Elie (ed.) (2000), The Six-Day War and world Jewry, Bethesda: University Press of Maryland.

Matus, Mario (1993), Tradición y adaptación. Vivencias de los sefaradies en Chile, Santiago: Comunidad Israelita Sefaradi de Chile y Universidad de Chile.

Navarro-Rosenblatt, Valeria (2017), "The Untold History: Voices of Non-affiliated Jews in Chile, 1940-1990", en R. Rein, S. Rinke y N. Zysman (eds.), The New Ethnic Studies in Latin America, Leiden: Brill, pp. 128-147.

- (2018), "Construcción de una memoria histórica. La celebración del cincuentenario de la colectividad israelita en Chile," Revista de Historia y Geografia, no 38, pp. 69-91.

Nes-El, Moshé (1988), "Natalio Berman, un líder sionista en Chile", Judaica Latinoamericana, Jerusalén: Magnes.

- (2005), "Judíos en la política chilena", Judaica Latinoamericana, $\mathrm{n}^{\circ}$ 5, Editorial Magnes-Universidad Hebrea de Jerusalén.

Peliowski, Beinish (2005), Amores congruentes, el inmigrante integrado, Santiago: Frasis.

Redlich, Shimon (1969), "The Jewish Antifascist Committee in the Soviet Union", Jewish Social Studies, vol. 31, $\mathrm{n}^{\circ} 1$.

Rubinstein, Joshua (2001), Stalin's Secret Pogrom, the postwar inquisition of the Jewish Anti-Fascist Committee, New Heaven: Yale University Press.

Schindler, J. (2017), Más allá de la diplomacia. La inédita historia de Samuel del Campo, Madrid: Príncipe.

Senderey, Moisés (1956), Historia de la colectividad israelita de Chile, Santiago: Dos Ydische Wort.

Stern, Steve J. (2009), Recordando el Chile de Pinochet. En visperas de Londres 1998, Santiago: UDP. 